\title{
Editorial
}

\section{Advanced Oxidation Processes for Wastewater Treatment}

\author{
Meenakshisundaram Swaminathan, ${ }^{1}$ Manickavachagam Muruganandham, ${ }^{2}$ and \\ Mika Sillanpaa ${ }^{3}$ \\ ${ }^{1}$ Department of Chemistry, Annamalai University, Annamalainagar 608002, India \\ ${ }^{2}$ Water and Environmental Technology (WET) Center, College of Engineering, Temple University, Philadelphia, PA 19122, USA \\ ${ }^{3}$ Laboratory of Green Chemistry, Faculty of Technology, Lappeenranta University of Technology, 50130 Mikkeli, Finland
}

Correspondence should be addressed to Meenakshisundaram Swaminathan; chemres50@gmail.com

Received 11 December 2012; Accepted 11 December 2012

Copyright (C) 2013 Meenakshisundaram Swaminathan et al. This is an open access article distributed under the Creative Commons Attribution License, which permits unrestricted use, distribution, and reproduction in any medium, provided the original work is properly cited.

Clean and nonpolluted water is one of the basic requirements for all living organisms including human beings. But its availability is a major problem nowadays. In the future, this problem will further increase due to global industrialization and population growth. Natural waters are being contaminated by the discharge of industrial, domestic, and agricultural wastes. Hence, at present it is very important to remove the pollutants and pathogens from wastewater to fulfill the needs for irrigation and industrial and domestic use. In the past years, conventional biological and physical treatment methods (adsorption, ultrafiltration, coagulation, etc.) have been used to remove the organic pollutants. These methods are not efficient and cost effective for wastewaters containing high concentration of more toxic pollutants. This requires some novel techniques to transfer the highly toxic pollutants chemically into benign species. Advanced oxidation processes (AOPs) are more efficient, cheap, and ecofriendly in the degradation of any kind of toxic pollutants. AOPs generate hydroxyl radical, a strong oxidant, which can completely degrade or mineralize the pollutants nonselectively into harmless products.

This special issue covered various AOPs used for the treatment of industrial wastewater, sewage, and landfill leachates. In 25 papers, authors have submitted original research articles in the following topics: (i) Fenton/photo-Fenton processes, (ii) $\mathrm{UV} / \mathrm{H}_{2} \mathrm{O}_{2}$ /ozone and sonolysis processes, (iii) Heterogeneous photocatalysis using $\mathrm{TiO}_{2} / \mathrm{ZnO}$ and their modified forms, and (iv) Use of different photoreactors for treatment.

A review on recent development in AOPs for water and wastewater treatment provides the latest developments on heterogeneous photocatalysis, Fenton/photo-Fenton processes, and $\mathrm{UV} / \mathrm{H}_{2} \mathrm{O}_{2}$ /ozonation processes.

A brief outline of all the accepted papers is provided as the following. D. H. Tseng et al. studied the influences of oxygen and hydrogen peroxide $\left(\mathrm{H}_{2} \mathrm{O}_{2}\right)$ on the degradation and mineralization of monochlorobenzene (MCB) in the $\mathrm{UV} / \mathrm{TiO}_{2}$ process. Their studies provided very useful information that the oxygen was a determining parameter for promoting the photocatalytic degradation.

N. R. Sanabria et al. reported development of pillared clays for wet hydrogen peroxide oxidation of phenol and its application in the posttreatment of coffee wastewater. From this study, they were able to conclude that catalytic wet hydrogen peroxide oxidation emerges as a viable alternative for posttreatment of coffee wastewater effluent.

Photo-Fenton and Fenton oxidation of recalcitrant industrial wastewater using nanoscale zero-valent iron was reported by $\mathrm{H}$. Hansson et al., The highest removal of COD and TOC ( $80 \%$ and $60 \%$, resp.) were achieved using photoFenton process.

W. S. Kuo and W. Y. Chen investigated Fresnel lens assisted by solar photocatalytic degradation of azo dye in aqueous $\mathrm{TiO}_{2}$ suspension.

Tertiary wastewater treatment by using combined process of UV photolysis and ozonation with biological aerating filter was studied by Z. Jing and S. Cao. They concluded that the combination of $\mathrm{UV} / \mathrm{O}_{3}$ oxidation with biological aeration filter was quite efficient in the organic pollutants removal for tertiary wastewater treatment. 
In "Microbiological evaluation of the effectiveness of sewage sludge sanitization with solar drying technology," authors estimated the sanitization effectiveness of the process of solar drying of sludge on technical scale in Poland, based on the inactivation kinetics of some test bacteria and parasite eggs.

C. D. Stan et al., investigated degradation of mepiquat chloride pesticide wastewaters by heterogeneous and homogeneous photocatalysis.

The oxidation degradation of Rhodamine $\mathrm{B}$ by using $\mathrm{UV} / \mathrm{S}_{2} \mathrm{O}_{8}{ }^{2-}$ treatment system was studied by $\mathrm{X}$. Chen et al.

J. Naumczyk et al., studied the landfill leachates treatment by using the advanced oxidation processes (AOPs) such as $\mathrm{H}_{2} \mathrm{O}_{2} / \mathrm{UV}, \mathrm{O}_{3} / \mathrm{H}_{2} \mathrm{O}_{2}$, modified Fenton, and modified photoFenton methods. They concluded that modified photoFenton process was the most effective among the all AOPs investigated.

N. Kishimoto, E. Nakamura reported bromate formation from potassium bromide solution with or without $6.4 \mu \mathrm{M}$ of 4-chlorobenzoic acid by using six physicochemical oxidation processes, such as UV irradiation, single addition of hydrogen peroxide, ozonation, UV irradiation with hydrogen peroxide addition $\left(\mathrm{UV} / \mathrm{H}_{2} \mathrm{O}_{2}\right)$, ozonation with hydrogen peroxide addition $\left(\mathrm{O}_{3} / \mathrm{H}_{2} \mathrm{O}_{2}\right)$, and ozonation with UV irradiation $\left(\mathrm{O}_{3} / \mathrm{UV}\right)$.

M. Antonopoulou et al. studied the simultaneous photocatalytic reduction of $\mathrm{Cr}(\mathrm{VI})$ and oxidation of benzoic acid in aqueous suspensions using N-F-codoped $\mathrm{TiO}_{2}$, and simulated solar irradiation in the present study. Chemometric optimization tools such as response surface methodology (RSM) and experimental design were used to model and optimize selected operational parameters of this simultaneous redox process.

In "Energy effectiveness of direct $U V$ and $U V / H_{2} \mathrm{O}_{2}$ treatment of estrogenic chemicals in biologically treated sewage," the removal efficiency by direct UV and the $\mathrm{UV} / \mathrm{H}_{2} \mathrm{O}_{2}$ treatment was investigated in biologically treated sewage for the parabens, industrial phenols, sunscreen chemicals, and steroid estrogens in wastewater in a thorough setup. Removal effectiveness was found to increase with $\mathrm{H}_{2} \mathrm{O}_{2}$ concentration up to $60 \mathrm{mg} / \mathrm{L}$.

The electrochemical incineration of phenolic compounds using boron-doped diamond electrodes was studied by A. Medel et al. The results were compared to the photo-electroFenton process.

Z. Ding et al. have reported the preparation of a modified PTFE fibrous photo-Fenton catalyst and its optimization towards the degradation of organic dye. They found that increasing the $\mathrm{Fe}$ content or incorporation of $\mathrm{Cu}(\mathrm{II})$ ions could significantly improve the catalytic activity of the complexes.

The oxidation of landfill leachate by heterogeneous Fenton process using ceria-based catalysts was reported by $\mathrm{E}$. Aneggi et al., They concluded from their studies that the heterogeneous Fenton technique could be effectively used for the treatment of landfill leachate.

S. Palmas et al. investigated the adsorption of glycerol at $\mathrm{TiO}_{2}$, as well as its oxidative process during the contemporary water photo-electro-splitting for hydrogen production.
In "Photocatalytic degradation of aniline using $\mathrm{TiO}_{2}$ nanoparticles in a vertical circulating photocatalytic reactor," photocatalytic degradation of aniline in the presence of titanium dioxide and ultraviolet illumination was performed in a vertical circulating photocatalytic reactor. The LangmuirHinshelwood kinetic model was successfully applied. The reactor was used successfully in the treatment of a real petroleum refinery wastewater.

The photocatalytic reduction of $\mathrm{Cr}(\mathrm{VI})$ ions in aqueous solutions by using $\mathrm{UV} / \mathrm{TiO}_{2}$ process was investigated by C. $\mathrm{M}$. $\mathrm{Ma}$ et al. The influence of various experimental parameters on the photocatalytic reduction was studied.

In "Photocatalytic treatment of shower water using a pilot scale reactor," a pilot scale study of photocatalytic degradation of impurities in real shower water was performed using titanium dioxide as the photocatalyst in a continuous slurry recirculation mode. More than half of the total organic carbon (TOC) elimination was obtained after 6 hours of treatment. Importantly, photocatalysis was successfully transposed from bench scale to pilot scale.

In "A new photocatalytic system using steel mesh and cold cathode fluorescent light for the decolorization of azo dye Orange G," a new photocatalytic system was prepared by coating nanosized $\mathrm{TiO}_{2}$ particles on steel mesh support and using cold cathode fluorescent light irradiation in a closed reactor for the oxidation of azo dye C.I. Orange $\mathrm{G}$ (OG). Efficient color removal of the $\mathrm{OG}$ azo dye by the photocatalytic system with $\mathrm{TiO}_{2}$-coated temperature at $150^{\circ} \mathrm{C}$ was achieved at the optimal $\mathrm{TiO}_{2}$ dosage $60 \mathrm{~g} \mathrm{~m}^{-2}$. The $\mathrm{TiO}_{2}$ coated steel mesh could be used repeatedly over 10 times without losing the photocatalytic efficiency.

R. Liu et al. reported the preparation of $\mathrm{TiO}_{2}$ and $\mathrm{Ag}-\mathrm{TiO}_{2}$ by coprecipitation method. The synthesized photocatalysts were characterized by using suitable analytical techniques. The $E$. coli inactivation by using the synthesized photocatalyst was investigated.

R. M. Mohamed and M. A. Barakat synthesized the Pt-doped $\mathrm{ZnO} / \mathrm{SiO}_{2}$ photocatalysts and their photocatalytic activity was tested by using phenol as a model pollutant. The synthesized photocatalysts were characterized by using advanced analytical techniques.

$\mathrm{V}$. Naddeo et al. studied the degradation of diclofenac by using various advanced oxidation processes such as ozonation $\left(\mathrm{O}_{3}\right)$ and sonolysis (US) and their combined application (US $+\mathrm{O}_{3}$ ).

C. Y. Lee et al. studied methylene blue decomposition by using novel microwave/UV/DO/ $/ \mathrm{TiO}_{2}$ photocatalyst hybrid system. Authors discussed the effect of $\mathrm{TiO}_{2}$ dosage, the influence of dissolved oxygen level, and the effect of microwave irradiation on the removal of methylene blue.

Q. Zhang et al. studied how the methylene blue dye degradation was affected by the high photon flux UV irradiation and results were compared with routine low photon flux photocatalytic process. Under the optimized conditions, the UV photocatalytic reaction $99 \%$ decolorization and $95 \%$ TOC removal of $20 \mathrm{mg} \mathrm{L}^{-1}$ methylene blue could be achieved in $30 \mathrm{~s}$ and $120 \mathrm{~s}$ of UV irradiation time, respectively. 


\section{Acknowledgments}

We are much grateful to the scientific colleagues, who reviewed the paper by sparing their valuable time. We are thankful to the Editorial Board for giving us an opportunity to edit this special issue and for their suggestions and guidance.

Meenakshisundaram Swaminathan Manickavachagam Muruganandham Mika Sillanpaa 

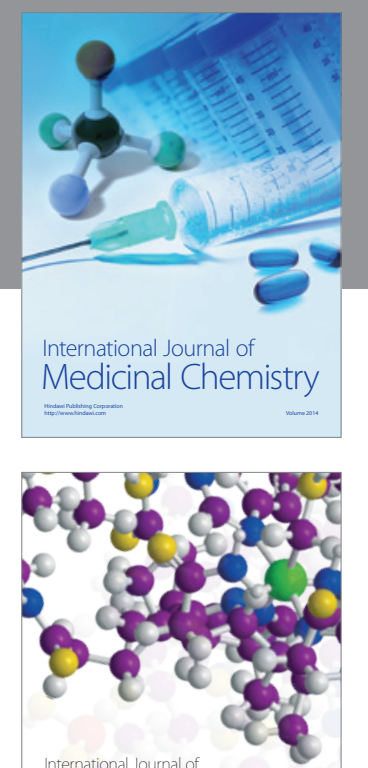

\section{Carbohydrate} Chemistry

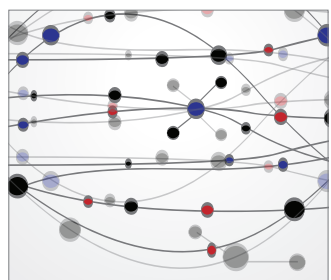

The Scientific World Journal
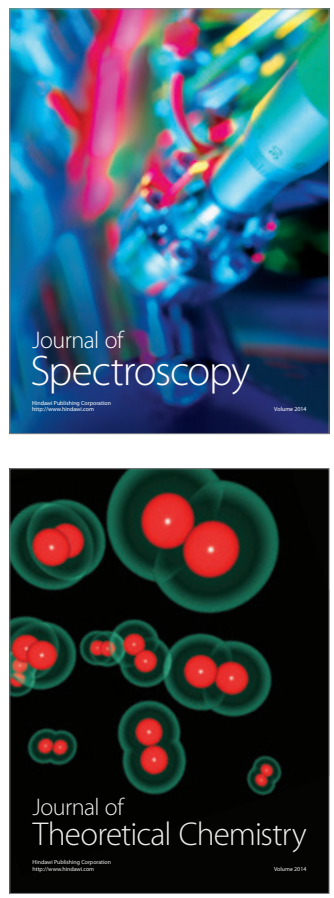
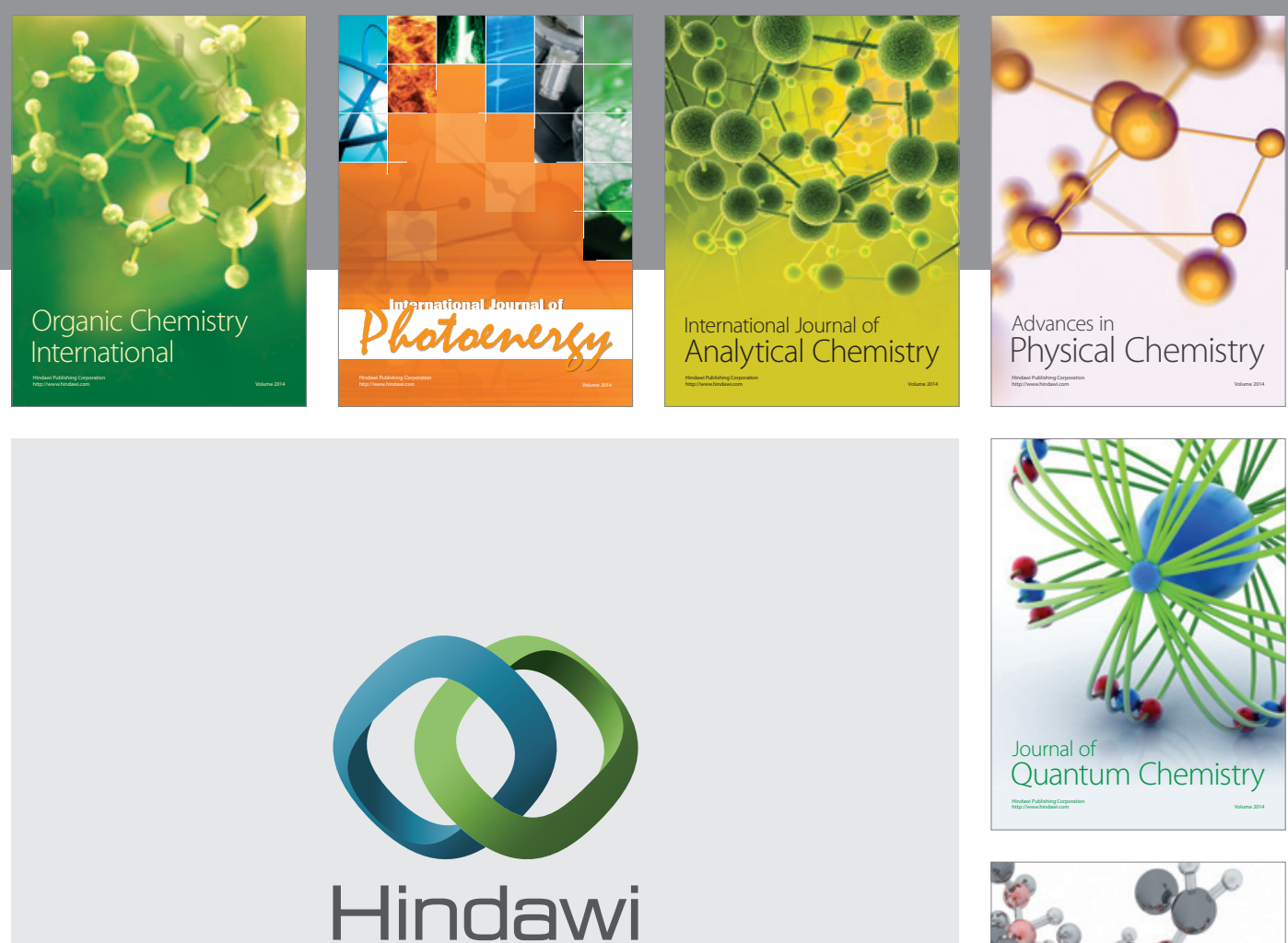

Submit your manuscripts at

http://www.hindawi.com

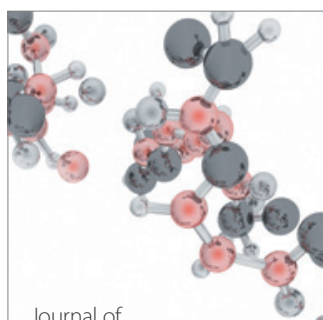

Analytical Methods

in Chemistry

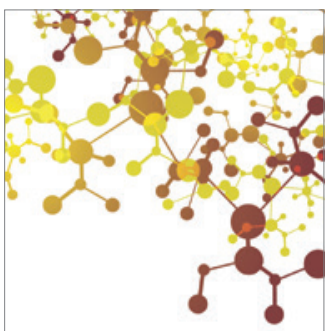

Journal of

Applied Chemistry

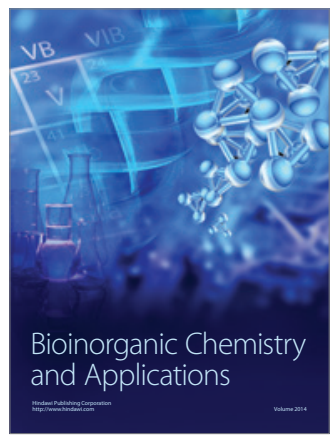

Inorganic Chemistry
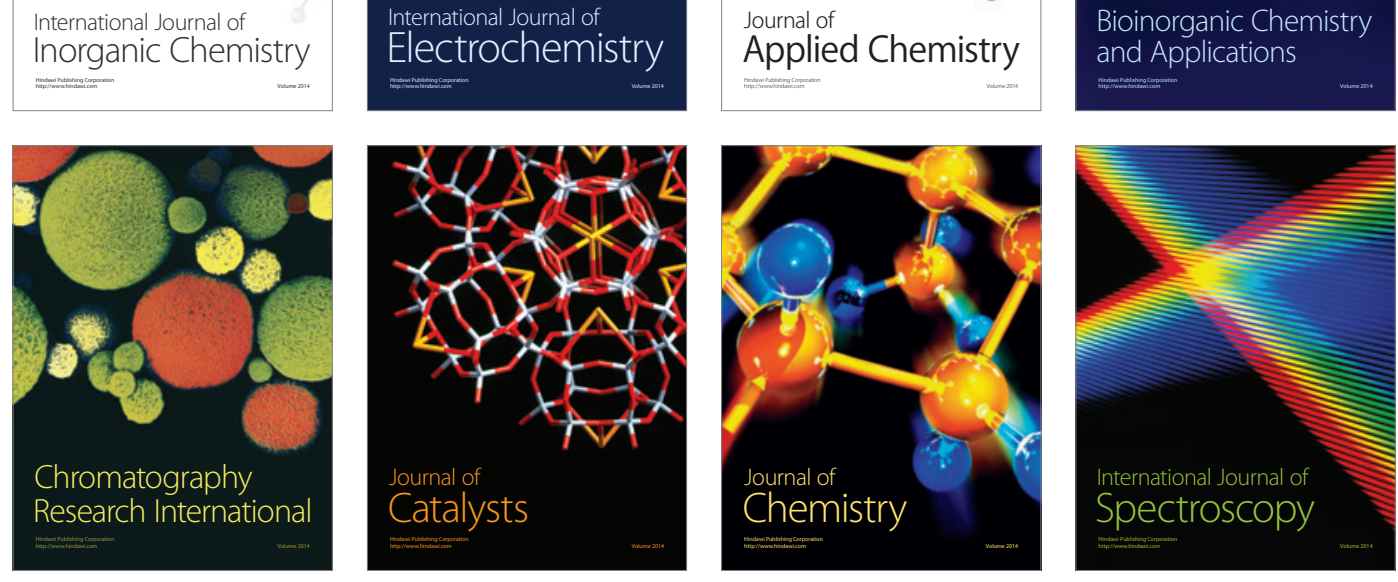